\title{
PROFESSORAS INICIANTES E BEM-SUCEDIDAS: FORMAÇÃO, DIDÁTICA E HABITUS
}

Fernanda Oliveira Costa Gomes ${ }^{1}$

\section{RESUMO}

O presente capítulo aborda a temática "a didática de professores iniciantes bem-sucedidos". Os resultados aqui apresentados são parte de uma pesquisa em nível de doutorado, no qual o objetivo foi identificar, junto aos professores iniciantes bem-sucedidos, as disposições presentes nas estratégias e características das ações didáticas para alcançar os objetivos de sua função. Os dados foram analisados a partir de conceitos da área da Sociologia e da Didática. Os referencias teóricos que embasaram a pesquisa foram Bourdieu (1994), Huberman (1992) e Marin (2005, 2014). A discussão realizada traz um aprofundamento acerca das práticas de professoras iniciantes, seus conhecimentos didáticos, assim como a importância de uma formação consistente e a influência do habitus no desenvolvimento do trabalho pedagógico.

Palavras-chave: Formação. Professoras-iniciantes. Didática. Habitus.

\section{INTRODUÇÃO}

O presente capítulo apresenta parte dos resultados de uma pesquisa de doutorado, abordando a temática "a didática de professores iniciantes considerados bem-sucedidos". É importante salientar que o termo bem-sucedido se refere ao sucesso pedagógico e não um sucesso ligado a questões econômicas ou de status. Portanto, destaca-se que obter sucesso na docência não significa a ausência de dificuldades no percurso, mas sim, ter a disposição de criar estratégias para superar os dilemas próprios da profissão.

A pesquisa teve como objetivo identificar, junto aos professores iniciantes bemsucedidos, as disposições presentes nas estratégias e características das ações didáticas para alcançar os objetivos de sua função, e ainda, analisar de maneira detalhada os recursos e ações didáticas utilizadas pelos professores na fase inicial da carreira.

Participaram da pesquisa três professoras iniciantes consideradas bem-sucedidas. As professoras foram indicadas por profissionais da área da Educação atuantes na supervisão, direção e formação de professores. Sendo que duas delas atuavam em salas de recuperação paralela, em uma escola pública da rede municipal da cidade de São Paulo.

Ambas estavam no sexto semestre do curso de Pedagogia, foram contratadas pela rede para atuar nas salas de recuperação, auxiliando alunos do ciclo de alfabetização que apresentavam dificuldades de aprendizagem. Já a outra professora, era concursada na rede municipal da cidade

\footnotetext{
${ }^{1}$ Doutora em Educação: História, Política, Sociedade - PUC-SP. E- mail: proffernanda.sumare@ gmail.com
} 
de São Paulo, e atuava na função de módulo, que consistia em substituir professores ausentes. No entanto, no decorrer da pesquisa, assumiu uma turma de $4^{\circ}$ ano de Ensino Fundamental, já que a regente da turma se afastou do cargo por problemas de cunho familiar.

Os procedimentos metodológicos utilizados para a coleta de dados foram: entrevistas e observações em salas de aulas; e os relatos das professoras, que obtidos por meio das entrevistas, possibilitaram a identificação do habitus. Já as observações foram cruciais para as análises das práticas e didática das professoras. Os dados foram analisados com base em três eixos de análise, sendo eles: as dificuldades, as estratégias didáticas e resultados do trabalho realizado por elas.

A pesquisa foi embasada teoricamente pelos estudos de Huberman (1992), Bourdieu (1994, 2013, 2014), e Marin (2005, 2014). Dos estudos de Huberman foram utilizados os conceitos de Exploração e Estabilização. Este autor realizou um estudo sobre o ciclo de vida dos professores, destacando as fases do início de carreira, a fase intermediária e a fase final da carreira. Já dos estudos de Bourdieu foi utilizado o conceito de habitus, e por fim, foram utilizados os estudos sobre didática de Marin, para realizar as análises das práticas das professoras.

A tese confirmou a hipótese de que a formação no Ensino Superior é essencial para o sucesso no desenvolvimento do trabalho docente, aliado às facetas do habitus desenvolvido pelo indivíduo em outras circunstâncias na composição de disposição da área didática, a partir de saberes contribuindo para o desempenho profissional do professor. Portanto, para se alcançar o objetivo da profissão, que consiste em garantir a aprendizagem dos alunos, se faz necessária uma formação que possibilite os conhecimentos para a autoanálise do trabalho e da prática, a criação de estratégias didáticas e a constante busca pelo conhecimento.

Em tempos em que se ouve falar em "professor com notório saber", e que não é necessário uma formação específica para exercer a profissão, a confirmação desta hipótese é também uma forma de resistência. A função de ensinar não se resume em transmitir conhecimento, portanto, ter um "notório saber" sem conhecimento didático, social, psicológico e político não garante o acesso dos alunos ao conhecimento. $\mathrm{O}$ ato de ensinar é processo formativo, transformador e emancipatório e, portanto, é preciso que um professor tenha a formação didática, social e política para que seus objetivos sejam alcançados.

\section{O INÍCIO NA CARREIRA DOCENTE: UMA DISCUSSÃO NECESSÁRIA}

As pesquisas que abordam o início de carreira têm crescimento modestamente nos últimos anos, no entanto, ainda existem diversas perguntas sobre a temática e muito a se explorar. O estudo de Mariano (2006) nos confirma o fato de que ainda são incipientes os estudos sobre professores iniciantes. Em sua dissertação, a pesquisadora analisou a produção do conhecimento sobre o 
referido tema, buscando junto às produções da ANPED (Associação Nacional de Pós-Graduação e Pesquisa em Educação) e do ENDIPE (Encontro Nacional de Didática e Práticas de Ensino) trabalhos que abordassem o processo de aprendizagem profissional da docência. $O$ pesquisador traçou um recorte temporal, entre os anos de 1995 até o ano de 2004, e sua análise revelou o modesto crescimento do interesse sobre o tema. Mariano (2006) afirma que foram apresentados um total de 145 trabalhos na ANPED no ano de 1995, sendo que nenhum deles abordava a iniciação à docência. Em 1996, foram apresentados 174 trabalhos e, novamente, nenhum trabalho sobre iniciação docente. Já em 1997, foram apresentados 152 trabalhos, mas apenas um trabalho tratava o tema da iniciação à profissão docente. A pesquisa indica que de 1995 a 2004 foram apresentados um total de 2.314 trabalhos, e destes, apenas quatro discutiam sobre professor em início de carreira.

A análise realizada por Mariano (2006) concluiu que os trabalhos sobre professores iniciantes enfatizavam características como a socialização profissional, os saberes docentes e os sentimentos de sobrevivência e descoberta que marcam fortemente o início da carreira.

Considerando que até o ano de 2004 eram poucos os trabalhos sobre o início da profissão docente, como estaria a produção nos anos seguintes?

Toda pesquisa é considerada relevante por trazer aspectos inéditos, algo novo. Por esse motivo, fora realizada uma busca por trabalhos de mestrado e de doutorado sobre a temática "professores iniciantes". O mapeamento destes trabalhos aconteceu em sites de universidades e no site do Scielo.

No mapeamento foi perceptível que as pesquisas acerca do início da profissão docente referem-se aos seguintes temas: socialização entre pares e alunos; aspectos didáticos na profissão docente; sentimento de sobrevivência na profissão docente; superação de dificuldades na profissão e formação docente; e o curso de Pedagogia. Entretanto, são inexistentes trabalhos que tratam de forma empírica à didática e as práticas de ensino de professores iniciantes, percebendo, portanto, a relevância sobre um estudo que se propõem a realizar uma emersão em sala de aula, buscando compreender quais são as práticas e conhecimentos didáticos que caracterizam um professor bemsucedido em sua função.

Parte das pesquisas sobre iniciantes apresentam as dificuldades, esgotamento, sentimentos de solidão e de sobrevivência. A pesquisa de Gomes (2014) abordou justamente estes fatores, identificando que a professora iniciante desconhecia: o como manejar a sala, sobre o nível de aprendizagem de seus alunos, sobre a Didática, a organização dos conteúdos, o como fazer o planejamento de tempo de aula, como realizar o planejamento das ações durante as aulas, o como 
utilizar a autonomia, o como trabalhar com os métodos propostos pelas escolas, e as noções de psicologia infantil.

Os desafios da profissão docente são de diferentes naturezas e o início de carreira é, geralmente, um momento de descobertas, de erros e acertos, de testar possibilidades, mas algo despertou a curiosidade: alguns professores, mesmo no início de carreira, conseguem desenvolver um trabalho de boa qualidade, e, portanto, podem ser considerados bem-sucedidos. O que eles têm de diferente? Como eles realizam seu trabalho?

Partindo desta curiosidade, a seguinte problemática foi levantada: diante das dificuldades próprias da profissão docente já bastante estudadas, quais são os procedimentos ou estratégias de ensino que professores iniciantes considerados bem-sucedidos utilizam para alcançar os objetivos de sua profissão?

A fim de responder a esta questão, foram realizadas entrevistas e observações em sala de aula de três professoras do Ensino Fundamental I, em escolas municipais da cidade de São PauloSP. As professoras foram chamadas de Júlia, Alice e Sofhia. Estes nomes são fictícios para garantir o sigilo e proteger a identidade das professoras. Esse foi também o procedimento com os nomes dos alunos e escolas apresentadas na tese.

As entrevistas aconteceram durante os momentos de hora atividade das professoras e permitiram apresentar os relatos, experiências de vida, sentimentos, possibilitando identificar o habitus de cada uma delas. Já as observações foram transcritas, respeitando os acontecimentos em sala de aula e interações entre as professoras e seus alunos.

O referencial teórico da pesquisa utilizou os estudos de Huberman (1992) para compreender a fase inicial da carreira. Este autor desenvolveu um estudo sobre o ciclo de vida dos professores, do início ao fim de carreira. A leitura e estudo deste autor foram importantes não só para o desenvolvimento da tese, mas fora uma leitura esclarecedora sobre os dilemas do início de carreira, pois Huberman conseguiu identificar aspectos da carreira docente que grande parte dos professores ainda hoje vivem, e que muitas vezes se sentem sozinhos no percurso, e ao realizar essa leitura foi perceptível que sentimentos como solidão, choque da realidade, sentimento de sobrevivência, exploração e estabilização são fases próprias da carreira.

Dos estudos de Huberman (1992), foram utilizados os conceitos de exploração e estabilização, pois atendem aos objetivos da pesquisa sobre professores iniciantes bem-sucedidos. Segundo Huberman, a fase de exploração,

[...] consiste em fazer uma opção provisória, em proceder a uma investigação dos contornos da profissão, experimentando um ou mais papéis. Se esta fase for positiva passe-se a uma fase de estabilização, ou de compromisso (HUBERMAN, 1992, p. 37). 
Já a fase de estabilização pode ser compreendida como o momento em que,

As pessoas centram a sua atenção no domínio das diversas características do trabalho, na procura de um setor de focalização ou de especialização, na aquisição de um caderno de encargos e de condições de trabalho satisfatórias e, em vários casos, na tentativa de desempenhar papéis e responsabilidades de maior importância ou prestígio, ou mais lucrativas (HUBERMAN, 1992, p. 37).

Ou seja, o momento da exploração é aquele em que os professores se colocam num esforço de testar possibilidades, metodologias, posturas, formas de interação, portanto este momento consiste em "explorar o desconhecido", perceber quais são os melhores caminhos ou os melhores procedimentos. E, portanto, quando os resultados são positivos eles tendem a ser estabilizados, e do contrário poderão ser descartados.

Tais conceitos foram utilizados para identificar como as professoras exploravam este "mundo desconhecido" da escola, do processo de ensino, dos embates que existem na relação com alunos e que de algum modo interfere nos resultados do trabalho, e ainda, tais conceitos permitem identificar quais ações são testadas pelas professoras e consequentemente se tornam permanentes ou descartáveis.

Dos estudos de Bourdieu (1994, 2013, 2014), foi utilizado o conceito de habitus. O autor explicou que "a noção de habitus é uma noção muito antiga, visto que remota a Aristóteles, passando por São Tomás" (BOURDIEU; CHARTIER, 2012, p. 57).

De acordo com o sociólogo francês, o habitus pode ser definido como:

[...] sistemas de disposições duráveis, estruturas estruturadas predispostas a funcionar como estruturas estruturantes, isto é, como princípio gerador e estruturados das práticas e das representações que podem ser objetivamente "reguladas" e "regulares" sem ser o produto da obediência a regras, objetivamente adaptadas a seu fim sem supor a intenção consciente dos fins e o domínio expresso das operações necessárias para atingi-los e coletivamente orquestradas, sem ser o produto da ação organizadora de um regente (BOURDIEU, 1983, p. 61).

E ainda, o habitus pode ser considerado

[...] como um sistema de disposições duráveis e transponíveis que, integrando todas as experiências passadas, funciona a cada momento como uma matriz de percepções, de apreciações e de ações - e torna possível a realização de tarefas infinitamente diferenciadas, graças às transferências analógicas de esquemas, que permitem resolver os problemas da mesma forma, e às correções incessantes dos resultados obtidos, dialeticamente produzidas por esses resultados (BOURDIEU, 1983, p. 65).

O conceito de habitus foi importante para a análise dos dados, pois os agentes têm uma história individual, mas também uma história coletiva; e nesta história, acontece uma incorporação 
de estruturas sociais de categorização de pensamentos e juízos, esquemas de percepção e sistemas de valores. E tal incorporação faz com que o sujeito tenha reações de acordo com o habitus por ele incorporado. Tal fator possibilita a compreensão do como as experiências de vida das professoras poderão influenciar nas suas práticas em sala de aula, no exercício de suas funções. Bourdieu explica que "o habitus trata-se de um sistema aberto de disposições que estará submetido constantemente à experiência e, desse modo, transformando para essas experiências" (BOURDIEU, 2012, p. 62).

Dos estudos de Marin (2005, 2014), foram utilizados as pesquisas sobre didática e, em especial, o conceito de feições da didática, possibilitando identificar quais características e conhecimentos sobre didática, presentes nas ações das professoras.

De acordo com Marin, a Didática apresenta algumas feições que completam o conceito. A feição inacabada consiste em um permanente processo de construção dado que seu objeto constitui um desafio constante na elaboração de um corpo de conhecimentos próprios. As feições operativas, interventiva, orientadora das práticas diárias da Didática são conceituadas como áreas promissoras, capazes de contribuir para a sistematização de conhecimento sobre as ações e operações do complexo processo de ensinar e da forma pela qual elas revelam transformações de conhecimentos para servir a certas funções e condições pessoais e materiais necessários para compreensão das regras ou normas regentes de tais processos, na investigação e no ensino. Feição crítica, reflexiva caracteriza a Didática nos estudos contra dogmatismos e ideias superadas dos saberes puramente intuitivos ou míticos ou, ainda, quando os estudos partem de diferentes pontos problemáticos para o processo de ensinar e aprender sobre o trabalho do professor. Afeição criativa se apresenta quando a Didática se propõe à construção de projetos, objetos e formas de atuar sobre a realidade, desdobrando ou convertendo conhecimentos (sobre a sala de aula, o professor e os alunos) em elementos fundamentais do knowhow necessário ao professor. A feição de eficiência é esperada da Didática, seja para interferir no trabalho do professor em serviço transformando-o, seja para melhor preparo daqueles que pretendem se dirigir ao magistério. Em suma: é preciso "saber fazer bem". Já a feição dialética das perspectivas investigadora e formadora é pressuposta a partir da forma como são concebidas (MARIN, 2005 apud GOMES 2020, p. 57).

Apresentadas as bases teórica, metodológica e de revisão bibliográfica, serão apresentados a seguir os dados e análises resultantes da pesquisa sobre didática de professores iniciantes bemsucedidos.

\section{É POSSÍVEL OBTER SUCESSO NO INÍCIO DE CARREIRA?}

Como fora dito anteriormente, participaram da pesquisa três professoras iniciantes atuantes na rede municipal da cidade de São Paulo, às quais atribuímos os seguintes nomes: Júlia, Alice e Sofhia. Reiteramos que são nomes fictícios a fim de preservar os sujeitos. 
A partir deste momento serão apresentados os resultados da pesquisa. Os dados foram organizados sob três eixos de análise, sendo eles: as dificuldades encontradas no âmbito da sala de aula, as estratégias de superação das dificuldades, e por fim, os resultados do trabalho realizado pelas professoras iniciantes.

\section{AS DIFICULDADES E DILEMAS DO INÍCIO DE CARREIRA}

As professoras Alice e Sofhia trabalhavam na mesma escola e também estudavam na mesma turma do curso de Pedagogia, em uma Universidade particular da cidade de São Paulo. Quando ocorreu a pesquisa, ambas estavam no sexto semestre do curso de Pedagogia. Elas eram responsáveis por turmas de recuperação paralela, em que o objetivo era auxiliar os alunos com dificuldades de aprendizagem, provenientes dos $1^{\circ}, 2^{\circ}$ e $3^{\circ}$ anos do primeiro ciclo do Ensino Fundamental.

Durante as entrevistas ambas relataram que as dificuldades encontradas no início de carreira foram aspectos como: o número elevado de alunos com dificuldade de aprendizagem numa mesma turma, a indisciplina, baixa autoestima dos alunos e falta de auxílio dos colegas docentes.

As salas de aula das professoras de recuperação paralela eram constituídas por um grupo de aproximadamente 20 alunos com dificuldades de aprendizagem. Considerando que o objetivo deste trabalho seria o auxílio dos alunos com dificuldades, o número de 20 alunos por sala dificultou o trabalho das professoras, pois era necessário um acompanhamento minucioso a estes alunos e, muitas vezes particular, para que o objetivo do trabalho se efetivasse.

Outro fator que dificultou o trabalho das professoras foi a indisciplina dos alunos, que também engloba a questão da agressividade e violência entre os discentes. As professoras relataram que a indisciplina prejudica o desenvolvimento das aulas e consequentemente implica na defasagem no desenvolvimento das crianças. Conforme relata uma das professoras:

\footnotetext{
Não era nada fácil. Muitos professores falam que a indisciplina é o não aprendizado, ou seja, o aluno que precisa do reforço são os indisciplinados. E eu percebi que não era bem assim. Nem todo aluno indisciplinado tem dificuldade de aprendizagem. E o que acontecia era que nos mandavam os alunos mais indisciplinados, apenas por serem indisciplinados. (Professora Alice).
}

A baixa autoestima dos alunos que frequentavam as salas de recuperação paralela foi citada como fator preponderante, que influenciou no desenvolvimento do trabalho das professoras. Seus relatos revelaram que uma considerável parcela dos alunos encaminhados para a recuperação se consideravam incapazes de aprender. 
Tivemos que fazer um trabalho de desconstruir alguns preconceitos. Porque o que as crianças nos revelavam era que elas tinham vergonha de ir para o reforço, porque ali eram enviadas as crianças "burras", que não conseguiam aprender. Fizemos um trabalho de desconstruir. E havia professoras titulares que reforçavam esse estereótipo, de que vão para a sala de recuperação os alunos fracos. E haviam crianças que por causa da vergonha, se escondiam para não ir. Eles sofriam bullying por estarem no reforço (Professora Sofhia).

Outra característica que dificultou o trabalho das professoras foi a difícil socialização com seus pares. Em entrevista, a professora Sofhia relatou:

Quando comecei o trabalho com a turma de recuperação a turma era minha. Eu não era mais uma auxiliar. Era uma turma de reforço, mas a responsabilidade era toda minha. Eu e minha colega que trabalhávamos juntas sofremos exclusão, pois as demais professoras da escola não se aproximavam. Teve uma situação em que uma professora chegou a fechar a porta para que nós não escutássemos o que iria ser falado numa reunião pedagógica. Mas, depois as coisas mudaram a ponto de algumas professoras nos pedirem ajuda, com determinados alunos. Aos poucos fomos conquistando nosso espaço e o respeito do grupo (Professora Sofhia).

Já a professora Júlia era concursada e atuava na rede pública na cidade de São Paulo. No momento em que aconteceu a pesquisa, ela cumpria a função de professora de módulo, isto é, ela substituía professores ausentes. Entretanto, após alguns meses, a professora Júlia assumiu uma turma do quarto ano do Ensino Fundamental, pois a professora da turma se afastou temporariamente por motivos familiares. A professora se formou em uma Universidade Pública Federal, e há três anos trabalhava em redes públicas de educação. Logo após terminar o curso de Pedagogia, foi aprovada em dois concursos públicos, um deles na cidade de Guarulhos e o outro na cidade de São Paulo.

Tal fator possibilitou a Júlia experiências de naturezas diferentes, pois iniciou sua carreira na rede educacional da cidade de Guarulhos e, em seguida, assumiu um cargo na prefeitura de São Paulo. E uma das dificuldades iniciais da professora Júlia foi proveniente, justamente, deste processo.

Eu tenho dificuldade com indisciplina. Porque eu venho de um contexto de salas muito calmas, em Guarulhos-SP. Eu tive a experiência com indisciplina de alunos, na prefeitura de São Paulo. Eu fiz combinados, conversei, mas aqui num contexto em que diante da indisciplina você tem professores que berram, pegam uma régua e batem na mesa. Eu lido com a indisciplina com uma perspectiva piagetiana. Na minha formação eu estudei muito Vigotsky e Marx, mas eu gosto do Piaget. Porque ele mudou a minha visão sobre indisciplina. Eu fui testando. Em situação de conflito quando os alunos brigam por causa de um lápis. Eu faço eles se colocarem no lugar do outro e tentarem resolver seus próprios conflitos, porque do contrário eles sempre vão depender do adulto e consequentemente não desenvolve a autonomia. E isso é importante (Professora Júlia). 


\section{AS ESTRATÉgIAS PARA A SUPERAÇÃO DAS DIFICULDADES: COM BASE NA FORMAÇÃO E NO HABITUS}

Diante dos desafios e dificuldades na profissão cada professor busca explorar diferentes formas de trabalho, alternativas, procedimentos que possibilitem o sucesso almejado. No caso das professoras Alice e Sofhia essa fase da exploração resultou na identificação de metodologias que pudessem auxiliar os alunos das salas de recuperação, levando-os a superarem suas dificuldades, e, portanto, desenvolvendo suas potencialidades.

Alice e Sofhia identificaram que métodos como jogos, brincadeiras, escrita de cartas, análises de contas de água e luz, e a correção coletiva realizada na lousa, resultavam positivamente. Estas ações se estabilizaram nas práticas do cotidiano de suas aulas, e, portanto, eram constantemente utilizadas pelas professoras para planejar e desenvolver suas aulas.

Nós fazíamos atividades utilizando a escrita de cartas. Vestíamos de carteiro para entregar as cartas, e as demais professoras nos olhavam com ar de reprovação, alegando que as crianças não iriam aprender nada com isso. E destacavam: "Tinha que ser iniciante". Teve professor que chegou a dizer: 'segura tua onda'. Então eu tive que entender que eu não poderia querer ser aceita pelo professor do lado. Mas, no final de tudo, elas viram que crianças que não sabiam ler e escrever, agora escreviam cartas para alguns professores. Então, quando eu comecei a trabalhar como professora eu pensei vou fazer tudo o que eu puder para ajudar esses alunos, em tudo, o que não me ajudaram eu vou fazer diferente. (Professora Sofhia).

Uma característica importante nas ações das professoras foi a ênfase em afirmar que o erro é um fator a ser superado, e não, fator limitante na aprendizagem. Tanto a professora Sofhia quanto a professora Alice identificaram a necessidade de trabalhar a autoestima dos alunos, pois se estes alunos continuassem a acreditar na sua incapacidade de aprender pouco seria possível de avançar no desenvolvimento dos mesmos.

Quando eu era aluna (ensino básico) eu fui muito excluída na escola. E quando eu via a situação daqueles alunos eu me colocava no lugar deles. Minha família era muito pobre. Viemos do Paraná. Com 4 ou 5 anos já trabalhávamos na roça. E quando viemos para São Paulo fomos morar na favela. E quando íamos para a escola sofríamos bullying porque éramos chamados de favelados. Meus irmãos desistiram da escola por isso. Tinham vergonha de morar na favela. Meu pai achava desperdício de tempo ir para escola. Ir para escola era despesa. Sendo negra, favelada, então tinha... eu tenho muito cabelo, (risos) então quando alguém pegava piolho, era meu. Mesmo eu fazendo umas traças que me deixava parecendo uma japonesa, as meninas alegavam que era de mim que elas pegavam piolho. Já tinha toda essa identidade. Quase não se tinha negros na escola em 1977. [...] Eu achava que a escola não era para mim, porque não encontrava os meus lá. Eu tinha apelido de Pelé, Kuntakinte. Eu ia apontar meu lápis e a professora falava: De novo Kuntakinte? Eu não sabia quem era. E ela falava que ia cortar meu pé. Por isso que eu me surpreendi quando me decidi por ser professora. Porque voltar para escola não seria fácil. Mas, foi bom voltar para superar isso. Eu conclui a escola por persistência, não por incentivo. A escola foi muito violenta. A minha dificuldade nunca era culpa da escola ou dos professores, a culpa era minha, da minha pobreza. Eu sempre tive que correr 
mais, me esforçar mais. Então terminar a escola foi uma vitória (Professora Sofhia).

As experiências vividas pela professora Sofhia, no que se refere à escola, foram negativas e retornar ao ambiente escolar, como professora, foi uma maneira de superar os traumas: "Eu quando aluna eu fui muito excluída na escola. E quando eu via a situação daqueles alunos eu me colocava no lugar deles. Então eu decidi que eu iria fazer por eles o que nunca fizeram por mim”.

Ambas as professoras desenvolveram um habitus de resistir a uma dinâmica de exclusão que se reproduz no âmbito escolar, e também transformaram suas experiências negativas, vividas no período em que eram alunas da escola básica, em estratégias para não permitir que seus alunos vivessem os mesmos dilemas que elas viveram.

O Aluno Caio (Nome fictício) sempre fez as atividades comigo. E a professora dele se irrita porque ele faz as atividades comigo, mas não faz com ela. Uma vez ela me falou na frente dele: '- Esse menino não faz nada comigo, só dá trabalho!' E por causa disso, ele ficou muito chateado e eu conversei com ele. Um dia eu o chamei e perguntei: 'Porque você não faz a lição com sua professora?' E ele me falou assim: 'Ah, Professora! Ela fala que eu não sei fazer, então eu não faço'. E eu respondi para ele assim: 'Caio, então vamos mostrar para ela que você pode, que você consegue fazer, para que ela tenha orgulho de você, como eu tenho?' E agora, ele faz tudo (Professora Alice).

Já a estratégia da professora Júlia foi utilizar conhecimentos construídos no PIBID (Programa Institucional de Bolsa de Iniciação à Docência) para elaborar suas metodologias e dinâmicas de aula.

Então, eu fui meio que descobrindo como fazer num percurso solitário. Eu pegava algumas experiências que tinha feito na faculdade e no PIBID e montava as atividades. Então, eu fiz PIBID de matemática, então eu tenho muito mais facilidade em matemática por isso. No PIBID eu descobri algumas coisas de rotina, de planejamento (Professora Júlia).

Nas manifestações e ações da professora Júlia fica visível a 'perspectiva formadora', ou seja, a formação obtida na graduação fez com que a professora Júlia superasse uma dificuldade com relação à disciplina de Matemática, redefinindo características da identidade da professora que passou a ter a Matemática como sua disciplina preferida a ser ensinada. Isso interferiu diretamente e positivamente nas aulas da professora, pois ao ensinar a construção de gráficos para os alunos do quarto ano a professora demonstrou total domínio do conteúdo e da metodologia no ensino da matemática.

Parte do habitus da professora Júlia sempre esteve relacionado aos estudos, à pesquisa e a uma busca constante pelo saber: "A minha relação é com o saber. Obviamente que a criança faz parte deste processo, mas a minha relação principal é com o conhecimento". 


\section{CONSIDERAÇÕES FINAIS}

Eu acho importante estudar porque se não você se encaixa no sistema e começa a pensar como todo mundo. E a tendência é começar a reproduzir falas e posturas de colegas. Então é necessário continuar estudando (Professora Júlia).

O resultado do trabalho realizado pelas professoras culminou nos seguintes aspectos: motivação dos alunos no processo de aprendizagem; interação e participação nas aulas; frequência e permanência dos alunos nas aulas; e reconhecimento por parte da gestão com relação ao trabalho realizado pelas professoras.

Programas de formação como o PIBID e residências pedagógicas foram apontados como recursos importantes na formação das professoras. Um fator importante que indica sucesso no trabalho de um professor é a própria manifestação do aluno. Durante as aulas, houve em diferentes momentos manifestações dos alunos, que afirmavam que tinham vergonha de frequentar as aulas de reforço, mas no decorrer do percurso perceberam que estava aprendendo, e a partir de então, sentiam prazer em estar nas aulas. Também nas aulas da professora Júlia, os alunos manifestaram o desejo de continuar a ter aulas com a professora, alegando gostar dela e de suas aulas.

Os resultados da pesquisa confirmaram a hipótese de que a formação no Ensino Superior é essencial para o sucesso no desenvolvimento do trabalho docente, aliado às facetas do habitus, desenvolvido pelo indivíduo em outras circunstâncias na composição de disposição da área didática a partir de saberes, contribuindo para o desempenho profissional do professor.

A Escola é uma instituição complexa, de relações sociais complexas, com problemas e dilemas provenientes da sociedade. E para trabalhar e cumprir a função de professor nesta instituição é extremamente importante uma formação que proporcione aos profissionais que ali atuam as condições de análise social, política, psicológica e didática.

O sucesso no início de carreira das professoras pesquisadas foi o resultado de uma formação consistente e de um habitus que resiste a toda e qualquer forma de exclusão e preconceitos. As professoras apresentaram a consciência de que sua função e seu trabalho são a garantia do acesso democrático ao conhecimento, o que fará toda a diferença na vida de seus alunos.

\section{REFERÊNCIAS}

BOURDIEU, Pierre. Esboço de uma Teoria da Prática. In: ORTIZ, Renato (Org.). A sociologia de Pierre Bourdieu, São Paulo: Editora Ática, 1994, n. 39, p. 46-86.

. Espaço social e espaço simbólico. In: Razões práticas: sobre a teoria da ação. Campinas, SP: Papirus, 1996. 
. É possível um ato desinteressado? In:

Razões práticas: sobre a teoria da ação. Campinas, Papirus, 1996, p.137-156.

BOURDIEU, P.; CHARTIER, R. Habitus e campo. In: O sociólogo e o historiador. Belo Horizonte: Autêntica Editora, 2012 , p. 57-68.

BOURDIEU. P. A Distinção: crítica social do julgamento. 2 ed. Porto Alegre, RS: Zouk, 2013.

GOMES, Fernanda Oliveira Costa. 2020. Professoras iniciantes e bem-sucedidas: Análise das estratégias didáticas de professores bem-sucedidas no início de carreira. Tese (Doutorado em Educação: História, Política, Sociedade). São Paulo. Pontifícia Universidade Católica de São Paulo / Programa de Estudos Pós Graduados em Educação: História, Política, Sociedade.

HUBERMAN, M. O ciclo de vida profissional dos professores. In: NÓVOA, António (Org.). Vidas de professores. Portugal: Porto Editora, 1992.

MARIANO, A. L. S. A construção do início da docência: um olhar a partir das produções da ANPED e do ENDIPE. São Paulo. Universidade Federal de São Carlos, São Carlos, 2006. (Dissertação de Mestrado).

MARIN, A.J. Redimensionamento da Didática a partir da prática de ensino. In: MARIN, A.J. (Coord.). Didática e trabalho docente. Araraquara: Junqueira \& Marin, 2005, p.57-65.

. A busca de fundamentos e do objeto da Didática - algumas anotações a respeito de estudos e pesquisas sobre o trabalho docente. In: MARIN, A.J. (Coord.). Didática e trabalho docente. Araraquara: Junqueira \& Marin,2005, p. 150- 158.

. O curso de Pedagogia em foco: fragilidades constantes e urgências da formação. In: CAVAlCANTE, M. M. D. et al. (Org.). Didática e Prática de Ensino: diálogos sobre a escola, a formação de professores e a sociedade. 1ed. Fortaleza: ENDIPE, 2014, v. 1, p. 1141- 1154. 